Check for updates

Cite this: RSC Adv., 2019, 9, 36171

Received 14th September 2019 Accepted 29th October 2019

DOI: $10.1039 / c 9 r a 07398 a$

rsc.li/rsc-advances

\section{A molecular understanding of the interaction of typical aromatic acids with common aerosol nucleation precursors and their atmospheric implications $\dagger$}

\author{
Hetong Wang, ${ }^{\mathrm{ab}}$ Xianwei Zhao, ${ }^{\mathrm{b}}$ Chenpeng Zuo, ${ }^{\mathrm{b}}$ Xiaohui Ma, ${ }^{\mathrm{b}}$ Fei Xu, (D) *ab \\ Yanhui Sun (D) ${ }^{\mathrm{c}}$ and Qingzhu Zhang (D) ${ }^{\mathrm{b}}$
}

Aromatic acids, which are generated from numerous anthropogenic emissions and secondary transformations, have been considered to play a crucial role in new particle formation. In this study, we performed theoretical calculations at the PW91PW91/6-311++G(3df,3pd) level to investigate the interaction between typical aromatic acids namely benzoic acid (BA), phenylacetic acid (PAA), phthalic acid (PA), isophthalic acid (mPA), and terephthalic acid (PTA) and common atmospheric nucleation precursors namely sulfuric acid $(\mathrm{SA})$, water $\left(\mathrm{H}_{2} \mathrm{O}\right)$, ammonia $\left(\mathrm{NH}_{3}\right)$, methylamine $(\mathrm{MA})$, dimethylamine (DMA), and trimethylamine (TMA). The geometric analysis, Gibbs free energy analysis, $\mathrm{OH} / \mathrm{NH}$-stretching vibrational frequency calculation, and atoms in molecules (AIM) analysis were conducted to determine the interactions in the complexes. The heterodimers formed a six to eight membered ring through four types of hydrogen bond, and the bond strength could be ranked in descending order: $\mathrm{SO}-\mathrm{H} \cdots \mathrm{O}>\mathrm{O}-$ $\mathrm{H} \cdots \mathrm{O} / \mathrm{N}>\mathrm{N}-\mathrm{H} \cdots \mathrm{O}$. The BA/PAA/mPA/PTA-SA complexes had the lowest Gibbs free energy values. PA was more likely to interact with $\mathrm{NH}_{3}$ or amines rather than $\mathrm{SA}$ due to an intra-molecular hydrogen bond. Additionally, the aromatic acids have similar ability to interact with $\mathrm{SA}$ and $\mathrm{NH}_{3}$ as monocarboxylic/ dicarboxylic acid. The formation potential of the heterodimers from aromatic acids with common nucleation precursors in ambient atmosphere was investigated.

\section{Introduction}

Atmospheric aerosols can substantially increase the concentration of cloud condensation nuclei (CCN) and may affect the Earth's climate. ${ }^{\mathbf{1 - 4}}$ Gas-phase nucleation is a key research area, and new particle formation (NPF) through nucleation is a vital source of atmospheric aerosols. ${ }^{5}$ However, the NPF process in the atmosphere, which includes multiple components, is highly complex. Although several investigations have been conducted on this process, the precise mechanisms and substances involved at the molecular level are still not adequately understand.

${ }^{a}$ Shenzhen Research Institute of Shandong University, Shenzhen 518057, P. R. China. E-mail: xufei@sdu.edu.cn; Fax: +86-532-5863198

${ }^{b}$ Environment Research Institute, Shandong University, Qingdao 266237, P. R. China ${ }^{c}$ College of Environment and Safety Engineering, Qingdao University of Science \& Technology, Qingdao 266042, P. R. China

$\dagger$ Electronic supplementary information (ESI) available: The minimum energy configurations of monomer. Geometric parameters of the $\mathrm{O}-\mathrm{H} \cdots \mathrm{O}$ intra-molecular hydrogen bonds in the PA-containing complexes. Intra-molecular bonded OH-stretching wavenumbers and red shifts of PA-containing complexes. Atoms in molecules (AIM) parameter analysis for the intra-molecular hydrogen bonds of PA-containing complexes. Cartesian coordinates of the minimum energy configurations. See DOI: 10.1039/c9ra07398a
To explain the nucleation mechanisms, binary sulfuric acid (SA)-water $\left(\mathrm{H}_{2} \mathrm{O}\right)$, ternary SA- $\mathrm{H}_{2} \mathrm{O}$-ammonia $\left(\mathrm{NH}_{3}\right){ }^{6}$ and ion-induced nucleation, ${ }^{7,8}$ and nucleation enhanced by organic compounds have been proposed. ${ }^{9}$ The importance of SA in new particle formation has been widely investigated, and numerous studies have proven that SA is a crucial atmospheric nucleating species. ${ }^{\mathbf{1 , 1 0}}$ However, a gaseous SA concentration of more than $10^{5}$ molecules per $\mathrm{cm}^{3}$ is required to observe NPF in the atmosphere. ${ }^{\mathbf{1 1 , 1 2}}$ Therefore, the vital role of organic species in NPF has attracted considerable attention. On the basis on the experimental methods, research has been proven that atmospheric aerosol particles indeed contain a large amount of organic compounds. ${ }^{13-15}$ Experimental results obtained from such research have shown that organic acids play a key role in the initial growth stage of newly nucleated embryos, and this process is crucial for the subsequent step of particle growth through adsorption or heterogeneous reactions of other organic vapors. Additionally, quantum chemical calculations have demonstrated that an aromatic acid-SA cluster can reduce the nucleation barrier and that a binary $\mathrm{SA}-\mathrm{H}_{2} \mathrm{O}$ nucleation system can be enhanced by sub-ppb levels of organic acids simultaneously. ${ }^{9}$ 
Aromatic acids belong to a group of organic acids, which include monocarboxylic acids and dicarboxylic acids. Benzoic acid (BA) is a typical aromatic monocarboxylic acid, that is generated from numerous anthropogenic emissions, such as motor vehicles and fuel burning. ${ }^{16} \mathrm{BA}$ is also a secondary product of the photochemical degradation of aromatic hydrocarbons. ${ }^{17}$ Phthalic acid (PA), isophthalic acid (mPA), and terephthalic acid (PTA) are aromatic dicarboxylic acids, that have been extensively discovered in the ambient atmosphere. PA can be emitted from the oxidation of polycyclic aromatic hydrocarbons (PAHs), including benz $[a]$ anthracene and naphthalene. ${ }^{18-21}$ It can also be generated from the burning of biomass, combustion of coal, and exhaust of diesel engines. ${ }^{22}$ Furthermore, MPA and PTA are primarily produced from the direct emission of automobile exhaust and biomass burning; mPA can also be derived from secondary aerosols. ${ }^{23}$ Liu and Zeng demonstrated that aromatic acids may be transformed by interacting with common atmospheric oxidants $\left(\mathrm{O}_{3}, \mathrm{Cl}, \mathrm{NO}_{3}\right.$, and $\mathrm{OH}$ radicals) through heterogeneous or homogeneous reactions. ${ }^{24}$ Zhang et al. detected five types of aromatic acids in $\mathrm{PM}_{2.5}$ in the northern suburb of Nanjing during winter; the average total concentration of the detected aromatic acids was $(50.01 \pm 16.05) \mathrm{ng} \mathrm{m}^{-3}$, and the average concentrations of PA, mPA and PTA were (8.14 \pm 3.34$),(1.08 \pm 0.43)$, and $(34.54 \pm$ 12.79) $\mathrm{ng} \mathrm{m} \mathrm{m}^{-3}$, respectively. ${ }^{23}$ In addition, a study reported the detection of aromatic dicarboxylic acids in the Los Angeles ambient atmosphere. ${ }^{25}$ Zhang et al. verified that the nucleation rates of $\mathrm{SA}-\mathrm{H}_{2} \mathrm{O}$ systems can be extensively reinforced by the presence of a small quantity of aromatic organic acids. ${ }^{9} \mathrm{Xu}$ and Zhang verified that PA can interact with sulfuric acid and ammonia to playing a key role in aerosol nucleation. ${ }^{26}$ Therefore, further investigation regarding the role of aromatic acids in nucleation is worthwhile.

In the present study, we investigated the interaction of five aromatic acids namely BA, PAA, PA, mPA, and PTA with common atmospheric aerosol nucleation precursors $\left(\mathrm{SA}, \mathrm{H}_{2} \mathrm{O}\right.$, $\mathrm{NH}_{3}$, methylamine (MA), dimethylamine (DMA), and trimethylamine (TMA)) at the molecular level. By using density functional theory (DFT) methods, we conducted theoretical calculations of these complexes to determine geometric parameters, binding energies and Gibbs free energies. Subsequently, we used atoms in molecules analysis (AIM) to determine the electronic densities and hydrogen bonding interactions in the complexes. ${ }^{27,28}$

\section{Computational methods}

The chemical geometries for the investigated compounds were determined by an artificial bee colony algorithm software called ABCluster (artificial bee colony algorithm for cluster), which is used for the global optimization of atomic and molecular clusters. ${ }^{29,30}$ ABCluster is a useful tool for determining the geometry of a cluster with the lowest energy. Density functional theory (DFT) calculations were performed using the Gaussian 09 package. ${ }^{31}$ First, up to 1000 initially guessed structures were auto-generated and pre-optimized by the semiempirical PM6 method using ABCluster. Second, up to 100 conformations with relatively low energies were selected from the 1000 structures and subsequently optimized at the B3LYP/6-31g(d,p) level; their corresponding vibrational frequencies were calculated at the same level. Finally, the PW91PW91 density functional method with a $6-311++\mathrm{G}(3 \mathrm{df}, 3 \mathrm{pd})$ basis set was employed to further reoptimize the 10 most stable of the 100 optimized structures in order to derive the global minimum structure. Their corresponding thermal free energies $(\Delta G)$, thermal enthalpies $(\Delta H)$, zero-point vibrational energy (ZPVE), and binding energy (BE) were also obtained at the PW91PW91/6-311++G(3df,3pd) level. The BEs of the complexes were corrected with ZPVEs. Several basic clusters formation has been investigated at the M06-2X/6$311++\mathrm{G}(3 \mathrm{df}, 3 \mathrm{pd})$ level of theory and recommended to be a more reliable method for predicting the formation of binary and ternary clusters. ${ }^{32-34}$ The comparison of Gibbs free energy calculated by two different DFT theories in this study was shown in Table 2. The differences between the Gibbs free energies calculated at PW91PW91/6-311++G(3df,3pd) and M06-2X/6$311++\mathrm{G}(3 \mathrm{df}, 3 \mathrm{pd})$ were within $2.0 \mathrm{kcal} \mathrm{mol}^{-1}$, which proves the consistency of the two methods. In this study, the analysis of configurations and energies was carried out at PW91PW91/6$311++\mathrm{G}(3 \mathrm{df}, 3 \mathrm{pd})$ level of theory.

To describe the strength and various classes of the hydrogen bonds, we performed a topological analysis of the charge density by using the AIM2000 program package through atoms in molecules (AIM) theory. AIM theory has been recognized as a powerful method for obtaining a relatively clear understanding of hydrogen bonding interactions. ${ }^{27,28}$ Additionally, electron density properties at the bond critical point (BCP), bond critical point charge density $\rho(r)$, and Laplacian of charge density $\nabla^{2} \rho(r)$ serve as an indicator to describe hydrogen bonding. ${ }^{35}$

\section{Results and discussion}

\subsection{Geometric analysis}

The geometries of $\mathrm{SA}, \mathrm{H}_{2} \mathrm{O}, \mathrm{NH}_{3}, \mathrm{MA}$, DMA, and TMA as well as those of BA, PAA, PA, MPA, and PTA were optimized at the PW91PW91/6-311++G(3df,3pd) level using the Gaussian 09 package. Several possible configurations of the complexes were found, but only the most stable structures of the clusters are discussed in this paper. The minimum energy configurations of monomer are displayed in Fig. S1. $\uparrow$ The optimized structures of the heterodimers are shown in Fig. 1, and the geometric parameters of the clusters are presented in Table 1. The intramolecular $\mathrm{O}-\mathrm{H} \cdots \mathrm{O}$ hydrogen bonds of PA-containing complexes are displayed in Table S1. $\dagger$ Cartesian coordinates of the minimum energy configurations are shown in Table S4. $\dagger$

Aromatic acids and SA formed an eight-membered ring through a $\mathrm{SO}-\mathrm{H} \cdots \mathrm{O}$ and a $\mathrm{CO}-\mathrm{H} \cdots \mathrm{O}$ hydrogen bonds. For the PA-SA complex, the carboxyl group formed an intra-molecular $\mathrm{CO}-\mathrm{H} \cdots \mathrm{O}$ hydrogen bond with a second carboxyl group of PA apart from the eight-membered ring. For the aromatic acid$\mathrm{NH}_{3}$ /MA/DMA complexes, the carboxyl group in the aromatic acids and the nitrogen atom in $\mathrm{NH}_{3} / \mathrm{MA} / \mathrm{DMA}$ formed a $\mathrm{CO}-\mathrm{H} \cdots$ $\mathrm{N}$ hydrogen bond, and the $\mathrm{N}-\mathrm{H} \cdots \mathrm{O}$ hydrogen bond was formed between the hydrogen atom in $\mathrm{NH}_{3} / \mathrm{MA} / \mathrm{DMA}$ and the oxygen 


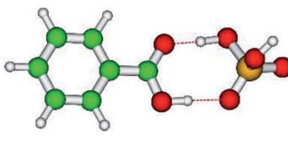

BA-SA

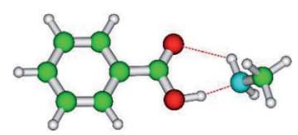

BA-MA

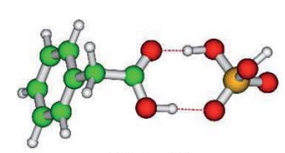

PAA-SA

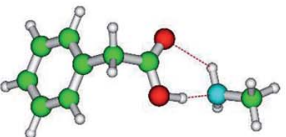

PAA-MA

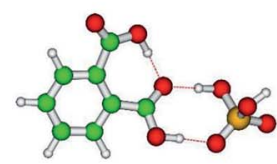

PA-SA

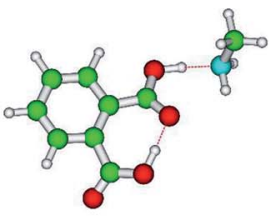

PA-MA

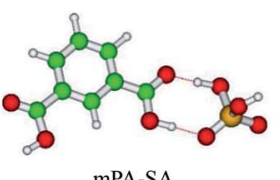

mPA-SA

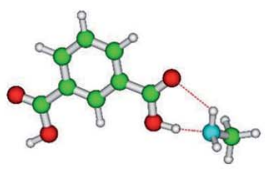

mPA-MA

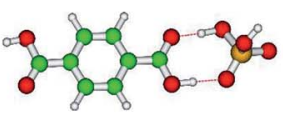

PTA-SA

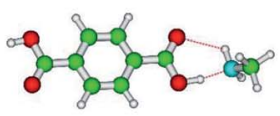

PTA-MA

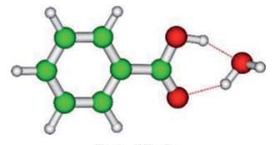

BA- $\mathrm{H}_{2} \mathrm{O}$

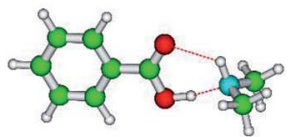

BA-DMA

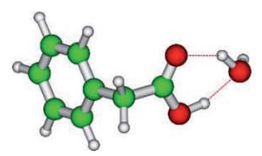

PAA- $\mathrm{H}_{2} \mathrm{O}$

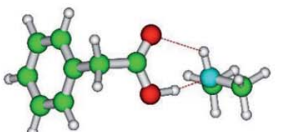

PAA-DMA

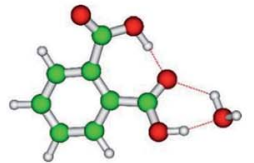

$\mathrm{PA}-\mathrm{H}_{2} \mathrm{O}$

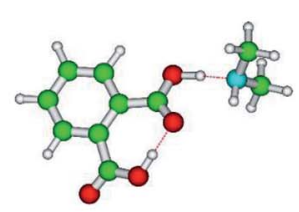

PA-DMA
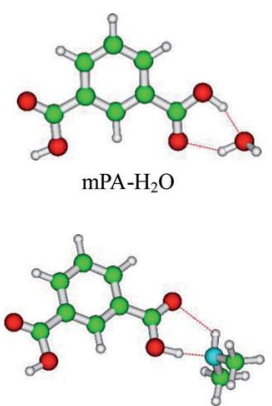

mPA-DMA

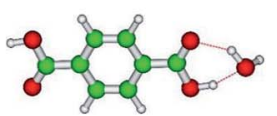

PTA- $\mathrm{H}_{2} \mathrm{O}$

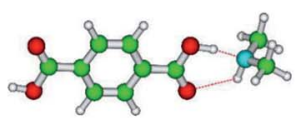

PTA-DMA

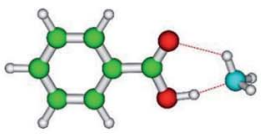

BA- $\mathrm{NH}_{3}$

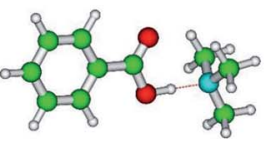

BA-TMA

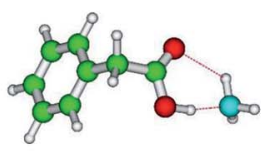

PAA- $-\mathrm{NH}_{3}$

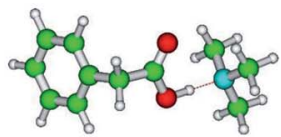

PAA-TMA

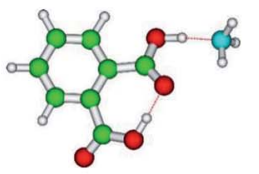

$\mathrm{PA}-\mathrm{NH}_{3}$

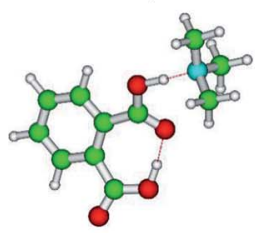

PA-TMA
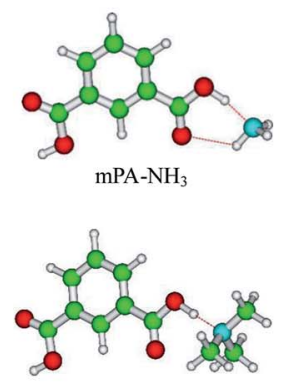

mPA-TMA

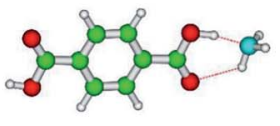

PTA-NH

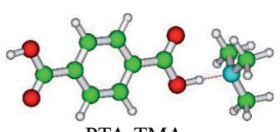

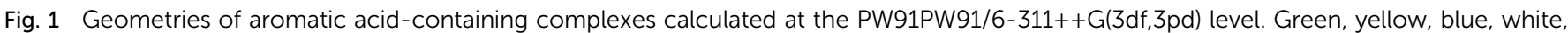
and red balls denote $\mathrm{C}, \mathrm{S}, \mathrm{N}, \mathrm{H}$, and $\mathrm{O}$ atoms, respectively.

atom in the carboxyl of the aromatic acid. All of these heterodimers formed a six-membered ring. For the aromatic acidTMA cluster, a seven-membered ring was produced through a CO- $\mathrm{H}^{\cdots \mathrm{N}}$ hydrogen bond and a $\mathrm{C}-\mathrm{H} \cdots \mathrm{O}$ hydrogen bond. PA contained one more intra-molecular hydrogen bond compared with the other aromatic acids. The aromatic acids formed a six- 
Table 1 Geometric parameters of the $\mathrm{SO}-\mathrm{H} \cdots \mathrm{O}, \mathrm{O}-\mathrm{H} \cdots \mathrm{O} / \mathrm{N}$, and $\mathrm{N}-\mathrm{H} \cdots \mathrm{O}$ hydrogen bonds in aromatic acid-containing complexes derived at the PW91PW91/6-311++G(3df,3pd) level. Angles are given in degrees $\left({ }^{\circ}\right)$; lengths and distances are given in angstrom ( $\AA$ )

\begin{tabular}{|c|c|c|c|c|c|c|c|c|c|c|c|}
\hline \multirow[b]{2}{*}{ Conformer } & \multicolumn{4}{|c|}{$\mathrm{SO}-\mathrm{H} \cdots \mathrm{O}$} & \multicolumn{4}{|l|}{$\mathrm{O}-\mathrm{H} \cdots \mathrm{O} / \mathrm{N}$} & \multicolumn{3}{|l|}{$\mathrm{N}-\mathrm{H} \cdots \mathrm{O}$} \\
\hline & $\Delta r(\mathrm{OH})^{a}$ & $r(\mathrm{HB})^{b}$ & $\theta(\mathrm{HB})^{c}$ & $d(\mathrm{O} \cdots \mathrm{O})^{d}$ & $\Delta r(\mathrm{OH})^{a}$ & $r(\mathrm{HB})^{b}$ & $\theta(\mathrm{HB})^{c}$ & $d(\mathrm{O} \cdots \mathrm{O})^{d}$ & $\Delta r(\mathrm{NH})^{e}$ & $r(\mathrm{HB})^{b}$ & $\theta(\mathrm{HB})^{c}$ \\
\hline BA-SA & 0.0863 & 1.4431 & 175.5 & 2.5036 & 0.0321 & 1.6380 & 178.4 & 2.6457 & & & \\
\hline $\mathrm{BA}-\mathrm{H}_{2} \mathrm{O}$ & & & & & $0.0297 / 0.0222$ & $1.7147 / 1.8450$ & $157.8 / 143.7$ & $2.6728 / 2.7073$ & & & \\
\hline $\mathrm{BA}-\mathrm{NH}_{3}$ & & & & & 0.0499 & 1.6789 & 168.1 & & 0.0042 & 2.2890 & 123.6 \\
\hline BA-MA & & & & & 0.0630 & 1.6329 & 169.3 & & 0.0052 & 2.3061 & 122.7 \\
\hline BA-DMA & & & & & 0.0721 & 1.6072 & 169.8 & & 0.0063 & 2.2809 & 123.9 \\
\hline BA-TMA & & & & & 0.0727 & 1.6096 & 179.3 & & & & \\
\hline PAA-SA & 0.0818 & 1.4577 & 175.8 & 2.5139 & 0.0321 & 1.6415 & 178.9 & 2.6504 & & & \\
\hline $\mathrm{PAA}-\mathrm{H}_{2} \mathrm{O}$ & & & & & $0.0293 / 0.0215$ & $1.7198 / 1.8582$ & $157.2 / 143.3$ & $2.6758 / 2.7168$ & & & \\
\hline PAA- $\mathrm{NH}_{3}$ & & & & & 0.0499 & 1.6792 & 167.8 & & 0.0040 & 2.3140 & 122.9 \\
\hline PAA-MA & & & & & 0.0634 & 1.6314 & 169.1 & & 0.0051 & 2.3257 & 122.3 \\
\hline PAA-DMA & & & & & 0.0724 & 1.6054 & 169.8 & & 0.0060 & 2.3136 & 122.8 \\
\hline PAA-TMA & & & & & 0.0729 & 1.6071 & 179.2 & & & & \\
\hline PA-SA & 0.0493 & 1.5675 & 177.3 & 2.5921 & 0.0333 & 1.6269 & 170.0 & 2.6360 & & & \\
\hline $\mathrm{PA}-\mathrm{H}_{2} \mathrm{O}$ & & & & & $0.0348 / 0.0122$ & $1.6610 / 2.0343$ & $163.4 / 131.2$ & $2.6460 / 2.7797$ & & & \\
\hline $\mathrm{PA}-\mathrm{NH}_{3}$ & & & & & 0.0667 & 1.6082 & 174.5 & 2.5221 & & & \\
\hline PA-MA & & & & & 0.0911 & 1.5434 & 175.2 & 2.5175 & & & \\
\hline PA-DMA & & & & & 0.1158 & 1.4880 & 175.5 & 2.5155 & & & \\
\hline PA-TMA & & & & & 0.1264 & 1.4699 & 177.2 & 2.5150 & & & \\
\hline mPA-SA & 0.0786 & 1.4621 & 175.9 & 2.5159 & 0.0330 & 1.6333 & 178.7 & 2.6420 & & & \\
\hline $\mathrm{mPA}-\mathrm{H}_{2} \mathrm{O}$ & & & & & $0.0310 / 0.0210$ & $1.7038 / 1.8633$ & $160.0 / 142.2$ & $2.6641 / 2.7135$ & & & \\
\hline $\mathrm{mPA}-\mathrm{NH}_{3}$ & & & & & 0.0537 & 1.6626 & 168.7 & & 0.0038 & 2.3267 & 121.6 \\
\hline mPA-MA & & & & & 0.0684 & 1.6129 & 170.2 & & 0.0047 & 2.3529 & 120.4 \\
\hline mPA-DMA & & & & & 0.0794 & 1.5824 & 170.9 & & 0.0059 & 2.3326 & 121.5 \\
\hline mPA-TMA & & & & & 0.0804 & 1.5837 & 178.7 & & & & \\
\hline PTA-SA & 0.0775 & 1.4661 & 175.9 & 2.5186 & 0.0330 & 1.6320 & 178.7 & 2.6408 & & & \\
\hline $\mathrm{PTA}-\mathrm{H}_{2} \mathrm{O}$ & & & & & $0.0311 / 0.0204$ & $1.7021 / 1.8723$ & 158.1/141.8 & $2.6634 / 2.7191$ & & & \\
\hline PTA- $\mathrm{NH}_{3}$ & & & & & 0.0541 & 1.6604 & 169.1 & & 0.0035 & 2.3457 & 120.9 \\
\hline PTA-MA & & & & & 0.0691 & 1.6110 & 170.2 & & 0.0048 & 2.3538 & 120.4 \\
\hline PTA-DMA & & & & & 0.0803 & 1.5804 & 170.7 & & 0.0059 & 2.3267 & 121.6 \\
\hline PTA-TMA & & & & & 0.0818 & 1.5792 & 178.8 & & & & \\
\hline
\end{tabular}

membered ring with $\mathrm{H}_{2} \mathrm{O}$ through a $\mathrm{CO}-\mathrm{H} \cdots \mathrm{O}$ hydrogen bond and an $\mathrm{O}-\mathrm{H} \cdots \mathrm{O}$ hydrogen bond. The bond length $r(\mathrm{H} \cdots \mathrm{B})$ in hydrogen bonds has been employed as an indicator of the hydrogen bond strength. Clearly, the hydrogen bond distances of all the complexes could be ranked as follows in ascending order: $\mathrm{SO}-\mathrm{H} \cdots \mathrm{O}<\mathrm{CO}-\mathrm{H} \cdots \mathrm{O} / \mathrm{N}<\mathrm{NH} \cdots \mathrm{O}$. This indicates that the $\mathrm{SO}-\mathrm{H} \cdots \mathrm{O}$ hydrogen bond was the strongest in the complexes. Gilli et al. identified the contact distance $d(\mathrm{O} \cdots \mathrm{O})$ between two oxygen atoms in a hydrogen bond as an indicator of hydrogen bond strength. ${ }^{36}$ In the same complexes in this study, the contact distance $d(\mathrm{O} \cdots \mathrm{O})$ of the $\mathrm{SO}-\mathrm{H} \cdots \mathrm{O}$ hydrogen bond was shorter than that of the $\mathrm{CO}-\mathrm{H} \cdots \mathrm{O}$ hydrogen bond. These results confirm that the SO-H $\cdots \mathrm{O}$ hydrogen bond was the strongest in the complexes. The $\mathrm{CO}-\mathrm{H} \cdots \mathrm{O} / \mathrm{N}$ hydrogen bond was stronger than the $\mathrm{N}-\mathrm{H} \cdots \mathrm{O}$ hydrogen bonds.

\subsection{Interaction energy}

The calculated binding energy (BE), zero-point vibrational energy (ZPVE), enthalpy of formation $\left(\Delta H_{298 \mathrm{~K}}^{\theta}\right)$ and Gibbs free energy of formation $\left(\Delta G_{298 \mathrm{~K}}^{\theta}\right)$ for the complexes are summarized in Table 2. The calculated $\Delta G_{298 \mathrm{~K}}^{\theta}$ values were $-7.99,-7.39,-4.47,-7.48$, and $-7.35 \mathrm{kcal} \mathrm{mol}^{-1}$ for BA-SA, PAA-SA, PA-SA, MPA-SA, and PTA-SA, respectively. This result indicates that the aromatic acids had the similar reactivity to interact with sulfuric acid except for PA. Apart from those observed for PA, the $\Delta G_{298}^{\theta}$ к values calculated for aromatic acid-SA complexes were more negative than those calculated for the aromatic acid- $\mathrm{NH}_{3} /$ amine complexes, indicating that the aromatic acids were more likely to interact with SA. This may have been due to the presence of intra-molecular hydrogen bonds, so PA is different from the other aromatic acids. The interaction of PA with $\mathrm{NH}_{3}$ /amine produced a lower Gibbs free energy compared with that produced by the PA-SA cluster. The $\Delta G_{298 \mathrm{~K}}^{\theta}$ values of the aromatic acid- $\mathrm{NH}_{3} /$ amine complexes were obviously quite similar. Among all aromatic acid- $\mathrm{NH}_{3} /$ amine clusters, apart from PAA-containing clusters, the aromatic acidDMA clusters had the lowest Gibbs free energy and the aromatic acid-TMA complexes had the highest Gibbs free energy in most clusters. This result proves that the interaction of aromatic acids with DMA was much stronger than those with $\mathrm{NH}_{3}, \mathrm{MA}$, 
Table 2 Binding energy (BE), zero-point vibrational energy (ZPVE), enthalpy of formation $\left(\Delta H_{298}^{\theta} \mathrm{K}\right)$ and Gibbs free energy of formation $\left(\Delta G_{298 \mathrm{~K}}^{\theta}\right)$ at $298.15 \mathrm{~K}$ and $1 \mathrm{~atm}$ for aromatic acid-containing complexes derived at the PW91PW91/6-311++G(3df,3pd) level. The Gibbs free energies also calculated at M06-2X/6-311++G(3df,3pd) level. Energy is given in $\mathrm{kcal} \mathrm{mol}^{-1}$

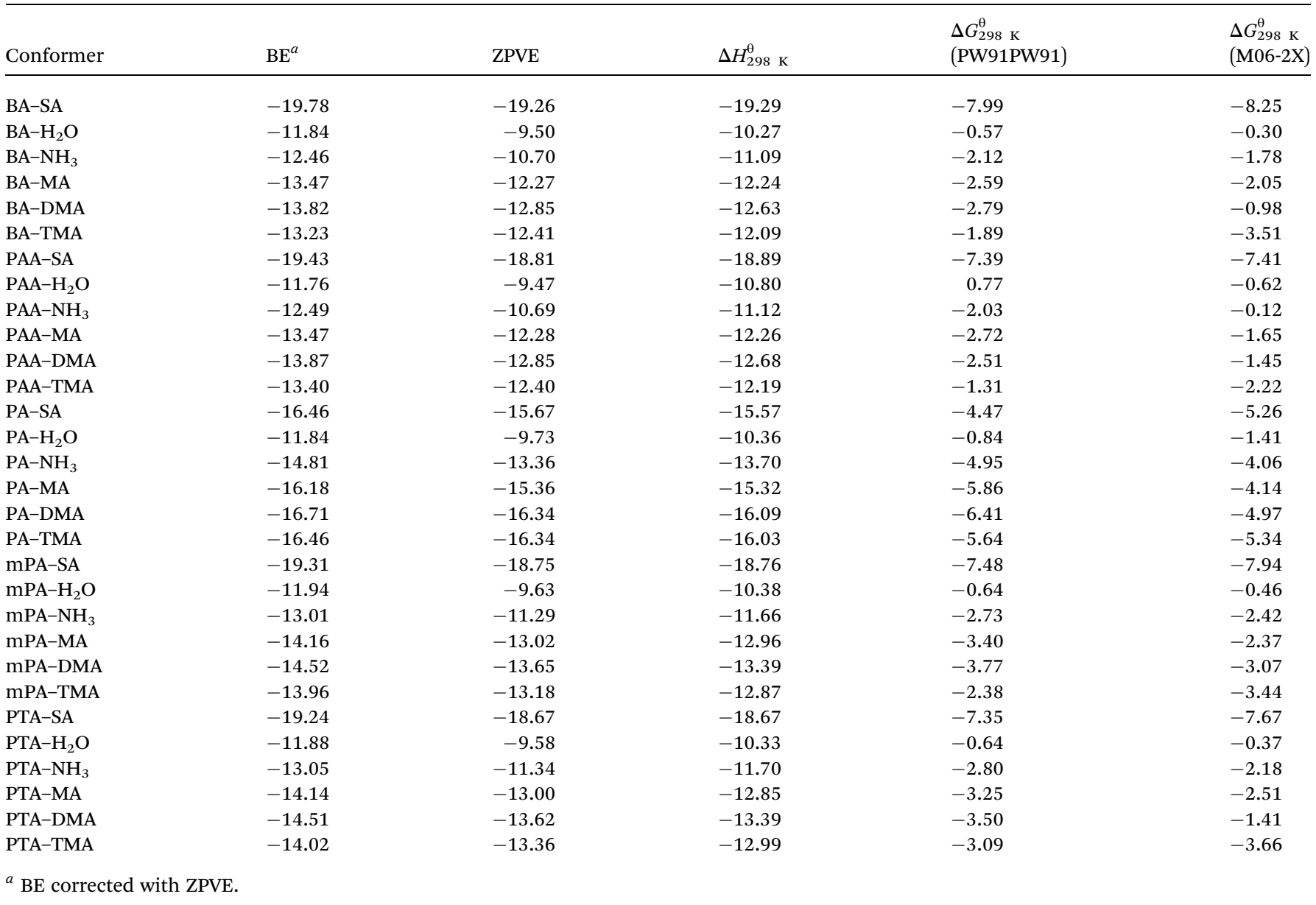

and TMA. All aromatic acid- $\mathrm{H}_{2} \mathrm{O}$ complexes, except for PAA, had the similar $\Delta G_{298 \mathrm{~K}}^{\theta}$ value; the $\Delta G_{298 \mathrm{~K}}^{\theta}$ value of PAA- $\mathrm{H}_{2} \mathrm{O}$ was slightly higher than those of the other aromatic acid- $\mathrm{H}_{2} \mathrm{O}$ clusters. The negative value of BEs indicates that the cluster was stable. Therefore, based on the BE, we can conclude that the aromatic acid-SA complexes were the easiest to form, followed by the aromatic acid-DMA complexes. The enthalpy $\Delta H_{298 \mathrm{~K}}^{\theta}$ of hydrogen bond formation is directly related to the stabilization energy of a complex. ${ }^{37}$ When we considered enthalpy, we could observe that the calculated values were consistent with the Gibbs free energy values of the complexes.

We compared the Gibbs free energy values of the aromatic monocarboxylic acids (BA, PAA)-SA complexes with those of the aromatic dicarboxylic acid (mPA, PTA)-SA complexes; we observed that the presence of the two carboxyls had little effect on the complexation process. However, increasing the number of carboxyl groups influenced the interaction of aromatic acids with $\mathrm{NH}_{3}$ or amines. For example, the $\Delta G_{298 \mathrm{~K}}^{\theta}$ value of the mPATMA cluster was lower than that of the PAA-TMA cluster by up to $4.33 \mathrm{kcal} \mathrm{mol}^{-1}$. The value of the Gibbs free energy value of the BA-containing complexes was slightly lower than that of the
PAA-containing complexes, signifying that methyl had an inhibitory role in the complexation process. Considering the different positions of the two carboxyl groups, the $\Delta G_{298}^{\theta}$ K value of the PA-SA complex $\left(-4.47 \mathrm{kcal} \mathrm{mol}^{-1}\right)$ was quite different from those of the mPA-SA $\left(-7.48 \mathrm{kcal} \mathrm{mol}^{-1}\right)$ and PTA-SA $\left(-7.35 \mathrm{kcal} \mathrm{mol}^{-1}\right)$ complexes. The reason is that the two carboxyl groups in the ortho-position could form an intramolecular hydrogen bond. Therefore, the presence of the intra-molecular hydrogen bond had a negative effect on the interaction of the aromatic acids and SA. This is consistent with the investigation of Jonas et al., no or weak presence of intramolecular hydrogen bond can stabilize the sulfuric acid cluster. ${ }^{38}$ However, the Gibbs free energy values derived for MPA-SA and PTA-SA were nearly the same. A possible reason is that, when the two carboxyl groups were in the meta-position and para-position, they were not sufficiently far apart to form an intra-molecular hydrogen bond. Therefore, only one carboxyl was involved in the hydrogen bond formation in both. For the $\mathrm{PA}-\mathrm{NH}_{3} /$ amines complexes, the complexation process was different from the complexation of the aromatic acids and SA. The presence of intra-molecular hydrogen bonds had a positive 
effect on the interaction of the aromatic acids and $\mathrm{NH}_{3}$ /amine. The Gibbs free energy value of PA-DMA was $6.41 \mathrm{kcal} \mathrm{mol}^{-1}$, whereas MPA-DMA was $-3.77 \mathrm{kcal} \mathrm{mol}^{-1}$.

According to the investigation by Nadykto and $\mathrm{Yu}$ at the PW91PW91/6-311++G(3df,3pd) level, ${ }^{39}$ the $\Delta G_{298 \mathrm{~K}}^{\theta}$ values obtained for formic acid $(\mathrm{HCOOH})-\mathrm{SA}$ and acetic acid $\left(\mathrm{CH}_{3}-\right.$ $\mathrm{COOH})-\mathrm{SA}$ were -6.44 and $-7.46 \mathrm{kcal} \mathrm{mol}^{-1}$, respectively. $\mathrm{Xu}$ et al. discussed the Gibbs free energy of a pyruvic acid $\left(\mathrm{CH}_{3}-\right.$ $\mathrm{COCOOH})-\mathrm{SA}$ cluster at the PW91PW91/6-311++G(3df,3pd) level, ${ }^{40}$ the value which was $-4.17 \mathrm{kcal} \mathrm{mol}^{-1}$. According to the calculation, the interaction between $\mathrm{CH}_{3} \mathrm{COCOOH}$ and $\mathrm{SA}$ was weaker than that between BA and SA. Although $\mathrm{CH}_{3} \mathrm{COCOOH}$ has a lower $\mathrm{p} K_{\mathrm{a}}$ value, the fact indicated that the acidity of monocarboxylic acid was not directly related to its cluster formation ability with SA. Comparing the Gibbs free energy values of BA-SA and PAA-SA clearly revealed that, aromatic monocarboxylic acids were basically similar or more likely to interact with SA compared with linear monocarboxylic acids. Xu et al. also reported that the Gibbs free energy values of malic acid ( $\mathrm{HOOCCHOHCH}_{2} \mathrm{COOH}$ )-SA and tartaric acid (HOOC$\mathrm{CHOHCHOHCOOH)-SA} \mathrm{were}-7.46$ and $-7.82 \mathrm{kcal} \mathrm{mol}^{-1}$, respectively, at the PW91PW91/6-311++G(3df,3pd) level. ${ }^{40}$ Miao et al. observed that the $\Delta G_{298}^{\theta} \mathrm{\kappa}$ values derived for oxalic acid (HOOCCOOH)-SA was -5.38 kcal mol ${ }^{-1}$ at the PW91PW91/6$311++\mathrm{G}(3 \mathrm{df}, 3 \mathrm{pd})$ level. ${ }^{41} \mathrm{PA}$ has a lower $\mathrm{p} K_{\mathrm{a}}$ value compared with MPA and PTA, however, the Gibbs free energies of PA-SA are about $3 \mathrm{kcal}^{\mathrm{mol}^{-1}}$ lower than mPA-SA and PTA-SA complexes. The $\mathrm{p} K_{\mathrm{a}}$ value of $\mathrm{HOOCCOOH}$ is lower than $\mathrm{MPA}$ and PTA, the formation of MPA-SA and PTA-SA heterodimers are easier than that of $\mathrm{HOOCCOOH}-\mathrm{SA}$. These all suggests that the acid strength does not directly correlate with its ability to form clusters with SA. We can conclude that the aromatic dicarboxylic acids had similar abilities to interact with SA than did the linear dicarboxylic acid. These results indicate that the affinities of aromatic acids to the SA were similar than those of linear monocarboxylic/dicarboxylic acid into SA. Moreover, the Gibbs free energy values of $\mathrm{HCOOH}-\mathrm{NH}_{3}, \mathrm{CH}_{3} \mathrm{COOH}-\mathrm{NH}_{3}$, and $\mathrm{CH}_{3} \mathrm{COCOOH}-\mathrm{NH}_{3}$ were calculated to be $-2.82,-2.35$, and $-0.96 \mathrm{kcal} \mathrm{mol}^{-1}$, respectively. ${ }^{39,40}$ For the dicarboxylic acids$\mathrm{NH}_{3}$ clusters, the $\Delta G_{298 \mathrm{~K}}^{\theta}$ value of $\mathrm{HOOCCHOHCH} \mathrm{COOH}_{2} \mathrm{CO}$ $\mathrm{NH}_{3}, \mathrm{HOOCCHOHCHOHCOOH}-\mathrm{NH}_{3}$ and $\mathrm{HOOCCOOH}-\mathrm{NH}_{3}$ were $-3.62,-5.41$, and $-5.14 \mathrm{kcal} \mathrm{mol}^{-1}$, respectively. ${ }^{40,42}$ Hence, aromatic acids have similar ability to interact with $\mathrm{NH}_{3}$ compared with that of monocarboxylic/dicarboxylic acids which is consistent with that of atomatic acid-SA and monocarboxylic/ dicarboxylic acid-SA. According to $\mathrm{Xu}$ et al. and Nadykto et al. ${ }^{\mathbf{4 3 , 4 4}}$ the Gibbs free energy value for $\mathrm{SA}-\mathrm{H}_{2} \mathrm{O}, \mathrm{SA}-\mathrm{NH}_{3}, \mathrm{SA}-$ MA, SA-DMA, and SA-TMA were $-0.28,-7.77,-11.03,-11.38$, and $-10.56 \mathrm{kcal} \mathrm{mol}^{-1}$, respectively. Aromatic acids-SA and SA$\mathrm{NH}_{3}$ clusters have a similar magnitude of Gibbs free energies. However, the interactions between aromatic acid and SA are weaker than those between SA and MA/DMA/TMA.

\subsection{Calculated $\mathrm{OH} / \mathrm{NH}$-stretching vibrational frequencies}

To clarify the variety classes and the strength of the different hydrogen bonds in the aromatic acid containing heterodimers, we used the red shift $(\Delta \tilde{v})$, which is the wavenumber difference between free and hydrogen bonded $\mathrm{OH}-/ \mathrm{NH}-$ stretching vibrational transitions $\left(\Delta \tilde{v}=\tilde{v}_{\text {monomer }}-\tilde{v}_{\text {dimer }}\right)$, to determine the interaction of different types of hydrogen bonds. ${ }^{4,46}$ The calculated $\mathrm{OH}^{-}$and $\mathrm{NH}$-stretching fundamental transition wavenumbers and the red shifts with respect to the heterodimers are summarized in Table 3 . The red shifts and the changes in the intra-molecular $\mathrm{OH}$ bond lengths in the PA complexes are presented in Table S2. $\dagger$

The red shifts of the $\mathrm{OH}$-stretching transitions of the $\mathrm{SO}-\mathrm{H} \cdot \cdots$ O hydrogen bonds of BA/PAA/mPA/PTA-SA were calculated to be within the range of $1336-1443 \mathrm{~cm}^{-1}$, and their corresponding intensities were increased by 70-84 times compared with those of the monomers. For the PA-SA complex, the red shift of the $\mathrm{OH}$-stretching transition was calculated to be $924 \mathrm{~cm}^{-1}$, and the intensity was calculated to be 50 times stronger than those of the monomers. This result is consistent with the Gibbs free energy value. Regarding the $\mathrm{CO}-\mathrm{H} \cdots \mathrm{O} / \mathrm{N}$ hydrogen bonds, formed between BA/PAA/mPA/PTA and $\mathrm{NH}_{3}$ or amines, the red shift of the $\mathrm{OH}$-stretching transition was within $918-1431 \mathrm{~cm}^{-1}$, and the intensity was increased by more than 7 times relative to those of the monomers. Thus, we could rank the hydrogen bonds according to their strength as follows: $\mathrm{SO}-\mathrm{H} \cdots \mathrm{O}>\mathrm{CO}-$ $\mathrm{H} \cdots \mathrm{O} / \mathrm{N}>\mathrm{N}-\mathrm{H} \cdots \mathrm{O}$. Additionally, the red shifts of the $\mathrm{OH}-$ stretching transition of the intra-molecular hydrogen bond in the PA-containing complexes were considerably smaller than those of the inter-molecular hydrogen bond, indicating that the inter-molecular $\mathrm{O}-\mathrm{H} \cdots \mathrm{O}$ hydrogen bond was stronger than the intra-molecular $\mathrm{O}-\mathrm{H} \cdots \mathrm{O}$ hydrogen bond.

\subsection{Topological analysis}

The AIM analysis serves as a tool to gain deep insights into the nature of hydrogen bond interactions. The AIM calculations were performed at the PW91PW91/6-311++G(3df,3pd) level according to the wavefunctions of the monomers and heterodimers. The AIM plots of all the heterodimers with bond critical points (BCPs), ring critical points (RCPs), and electron density paths are depicted in Fig. 2. The topological parameters, including electron density $\rho(r)$, Laplacian of electron density $\nabla^{2} \rho(r)$ at the BCPs, and changes in atomic charge $\Delta q(\mathrm{H})$ at the $\mathrm{H}$ atom determined using the PW91PW91 method, are listed in Table 4. The AIM parameters for the intra-molecular hydrogen bonds of the PA complexes are presented in Table S3. $\dagger$

For the aromatic acid-SA complexes, the electron densities $\rho(r)$ at the BCPs for $\mathrm{SO}-\mathrm{H} \cdots \mathrm{O}$ and $\mathrm{CO}-\mathrm{H} \cdots \mathrm{O}$ were within 0.0646-0.0903 and 0.0519-0.0536 a.u., respectively. The electron densities $\rho(r)$ at the BCPs for the $\mathrm{CO}-\mathrm{H} \cdots \mathrm{O}$ and $\mathrm{N}-\mathrm{H} \cdots \mathrm{O}$ hydrogen bonds were within the limits of $0.0597-$ 0.0804 and 0.0134-0.1053 a.u., respectively, in the aromatic acid- $\mathrm{NH}_{3} / \mathrm{MA} / \mathrm{DMA} / \mathrm{TMA}$ complexes. On the basis of the standard proposed by Koch and Popelier, ${ }^{47}$ for a hydrogen bond, the electron density $\rho(r)$ is usually within $0.002-0.040$ a.u. ${ }^{47,48}$ Clearly, the aforementioned $\rho(r)$ of the hydrogen bonds considerably exceed the upper limit of electron density values. The reason may be that the aromatic acids and SA/ $\mathrm{H}_{2} \mathrm{O} / \mathrm{NH}_{3} / \mathrm{MA} / \mathrm{DMA} / \mathrm{TMA}$ had strong hydrogen bond interactions. The values derived for the $\nabla^{2} \rho(r)$ for SO-H $\cdots \mathrm{O}$ and CO- 
Table $3 \mathrm{SO}-\mathrm{H} / \mathrm{O}-\mathrm{H} / \mathrm{N}-\mathrm{H}$ stretching wavenumbers and red shifts $\left(\mathrm{cm}^{-1}\right)$ of aromatic acid-containing complexes computed at the PW91PW91/ $6-311++G(3 d f, 3 p d)$ level

\begin{tabular}{|c|c|c|c|c|c|c|c|c|c|}
\hline Conformer & $\tilde{v}$ & $\Delta \tilde{\boldsymbol{v}}^{a}$ & $f_{\mathrm{D}} / f_{\mathrm{M}}{ }^{b}$ & $\tilde{v}$ & $\Delta \tilde{\boldsymbol{v}}^{a}$ & $f_{\mathrm{D}} / f_{\mathrm{M}}{ }^{b}$ & $\tilde{v}$ & $\Delta \tilde{\nu}^{a}$ & $f_{\mathrm{D}} / f_{\mathrm{M}}{ }^{b}$ \\
\hline $\mathrm{BA}-\mathrm{H}_{2} \mathrm{O}$ & & & & $3077 / 3372$ & $576 / 451$ & $12.9 / 18.5$ & & & \\
\hline $\mathrm{BA}-\mathrm{NH}_{3}$ & & & & 2725 & 928 & 7.3 & 3492 & 213 & 14.8 \\
\hline BA-MA & & & & 2513 & 1140 & 43.8 & 3483 & 19 & 16.2 \\
\hline PAA-SA & 2284 & 1381 & 69.8 & 3035 & 599 & 47.5 & & & \\
\hline $\mathrm{PAA}-\mathrm{H}_{2} \mathrm{O}$ & & & & $3070 / 3383$ & $564 / 440$ & $11.3 / 14.5$ & & & \\
\hline PAA- $\mathrm{NH}_{3}$ & & & & 2716 & 918 & 43.6 & 3493 & 21 & 13.2 \\
\hline PAA-MA & & & & 2498 & 1136 & 58.3 & 3482 & 19 & 14.8 \\
\hline PAA-DMA & & & & 2358 & 1276 & 68.3 & 3383 & 71 & 151 \\
\hline PAA-TMA & & & & 2341 & 1294 & 75.4 & & & \\
\hline PA-DMA & & & & 1828 & 1816 & 40.5 & & & \\
\hline PA-TMA & & & & 1745 & 1899 & 28.8 & & & \\
\hline mPA-SA & 2313 & 1352 & 83.1 & 3029 & 624 & 29.8 & & & \\
\hline $\mathrm{mPA}-\mathrm{H}_{2} \mathrm{O}$ & & & & $3055 / 3394$ & $597 / 429$ & $11.5 / 17.0$ & & & \\
\hline $\mathrm{mPA}-\mathrm{NH}_{3}$ & & & & 2665 & 987 & 28.9 & 3494 & 20 & 14.9 \\
\hline mPA-MA & & & & 2432 & 1212 & 37.1 & 3483 & 18 & 16.0 \\
\hline mPA-DMA & & & & 2269 & 1383 & 44.5 & 3386 & 68 & 145 \\
\hline MPA-TMA & & & & 2241 & 1411 & 48.4 & & & \\
\hline PTA-SA & 2329 & 1336 & 85.6 & 3027 & 624 & 18.2 & & & \\
\hline $\mathrm{PTA}-\mathrm{H}_{2} \mathrm{O}$ & & & & $3052 / 3404$ & $599 / 419$ & $6.9 / 16.6$ & & & \\
\hline PTA-NH ${ }_{3}$ & & & & 2658 & 994 & 17.0 & 3495 & 19 & 14.7 \\
\hline PTA-MA & & & & 2422 & 1230 & 21.7 & 3483 & 19 & 16.9 \\
\hline
\end{tabular}

$\mathrm{H} \cdots \mathrm{O}$ hydrogen bonds in the aromatic acid-SA complexes, were within the ranges of $0.0704-0.0971$ and $0.1065-0.1067$ a.u., respectively. For the aromatic acid- $\mathrm{NH}_{3} / \mathrm{MA} / \mathrm{DMA} / \mathrm{TMA}$ clusters, the $\nabla^{2} \rho(r)$ values obtained for the $\mathrm{CO}-\mathrm{H} \cdots \mathrm{O}$ and $\mathrm{N}-\mathrm{H} \cdots \mathrm{O}$ hydrogen bonds were in the range of from -0.0412 to 0.0617 and from 0.0442 to 0.0503 a.u., respectively. These values were almost within the range of Laplacian criteria (0.014-0.139 a.u.). ${ }^{47,48}$

\subsection{Atmospheric implication}

To explain the role of aromatic acids in the formation of heterodimers from aromatic acids with common nucleation precursors in the atmosphere, the mass-balance equation was used to evaluate the atmospheric implication. Take BA-SA cluster as an example, the [BA-SA] concentration can be expressed as follows:

$$
[\mathrm{BA}-\mathrm{SA}]=[\mathrm{BA}] \times[\mathrm{SA}] \mathrm{e}^{-\frac{\Delta G}{R T}}
$$

where $[\mathrm{BA}-\mathrm{SA}],[\mathrm{BA}]$, and $[\mathrm{SA}]$ are the atmospheric mixing ratios of BA-SA, BA, and SA, respectively. The mixing ratios in eqn (1) can be written out e.g. as $[\mathrm{SA}]=p(\mathrm{SA}) / p^{0}$, where $p(\mathrm{SA})$ is the $\mathrm{SA}$ partial pressure, and $p^{0}=1 \mathrm{~atm}$ is the reference pressure at which $\Delta G$ is computed. $\Delta G$ is the Gibbs free energy during the formation of the BA-SA cluster, $R$ is the molar gas constant in $J$ $(\mathrm{mol} \mathrm{K})^{-1}$, and $T$ is the temperature in $\mathrm{K}$.

Eqn (1) reveals that the concentration of the BA-SA complex is related to the concentrations of BA and SA and the value of the Gibbs free energy for cluster formation. The concentrations of $\mathrm{SA}, \mathrm{H}_{2} \mathrm{O}, \mathrm{NH}_{3}, \mathrm{MA}$, DMA and TMA in ambient atmosphere were approximately $1 \times 10^{7}, 2.46 \times$ $10^{14}, 1 \times 10^{11}, 1 \times 10^{9}, 1 \times 10^{9}$, and $1 \times 10^{9}$, respectively. The concentrations of BA, PAA, PA, mPA, and PTA were $1.05 \times$ $10^{3}, 7.50 \times 10^{8}, 4.16 \times 10^{1}, 5.47 \times 10^{0}$, and $1.71 \times 10^{2}$ molecule per $\mathrm{cm}^{3}$, respectively. ${ }^{49-51}$ The concentrations of the complexes from dimerization of aromatic acid and common nucleation precursor calculated by the mass-balance equation are listed in Table 5. For a given aromatic acid, the aromatic acid $-\mathrm{H}_{2} \mathrm{O}$ complexes had the highest concentrations in the ambient atmosphere, followed by the aromatic acid-SA, and aromatic acid- $\mathrm{NH}_{3} / \mathrm{DMA}$. When compared the concentration of aromatic acid- $\mathrm{NH}_{3}$ and aromatic acid-DMA clusters, for a given aromatic acid, the concentration of aromatic acid- $\mathrm{NH}_{3}$ heterodimer is higher than that of 


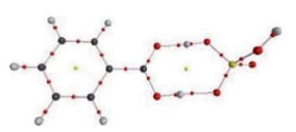

BA-SA

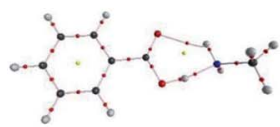

BA-MA

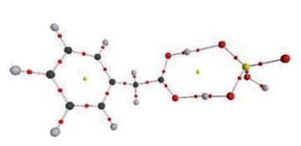

PAA-SA

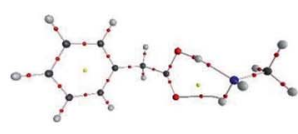

PAA-MA

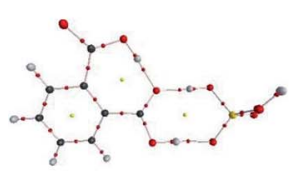

PA-SA

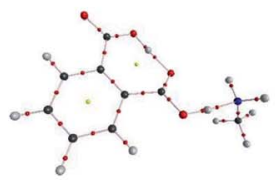

PA-MA

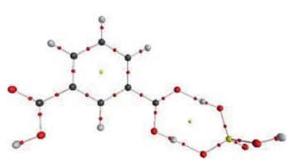

MPA-SA

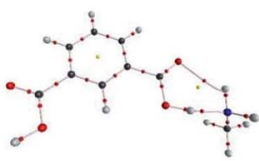

mPA-MA

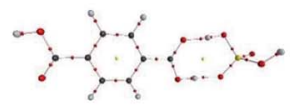

PTA-SA

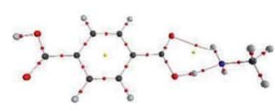

PTA-MA
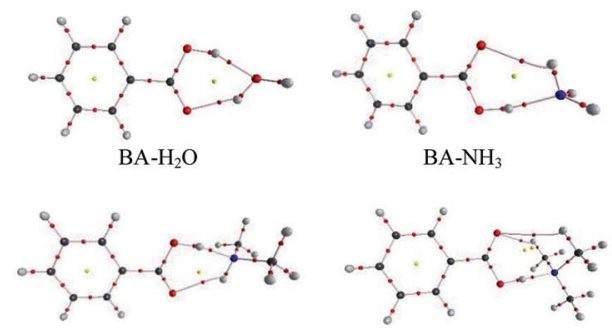

BA-DMA

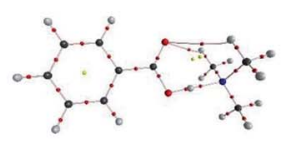

BA-TMA

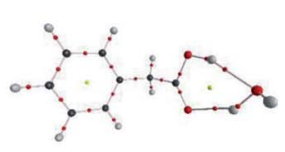

$\mathrm{PAA}-\mathrm{H}_{2} \mathrm{O}$

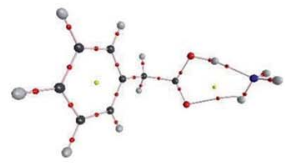

PAA-NH

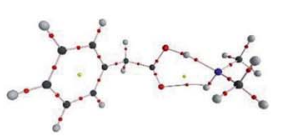

PAA-DMA

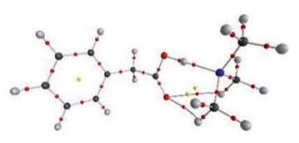

PAA-TMA

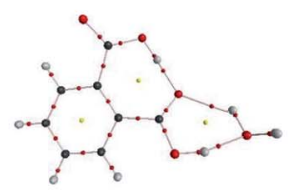

$\mathrm{PA}-\mathrm{H}_{2} \mathrm{O}$

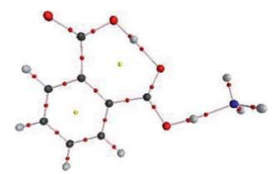

$\mathrm{PA}-\mathrm{NH}_{3}$

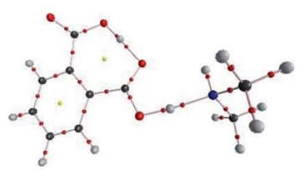

PA-DMA

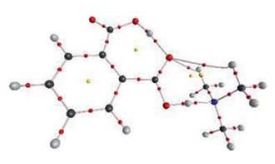

PA-TMA

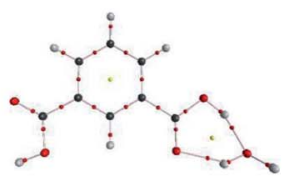

mPA- $\mathrm{H}_{2} \mathrm{O}$

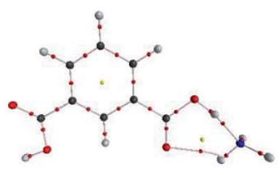

mPA- $\mathrm{NH}_{3}$

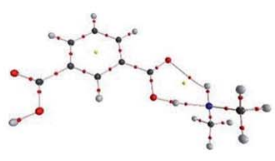

mPA-DMA

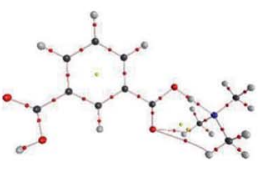

mPA-TMA

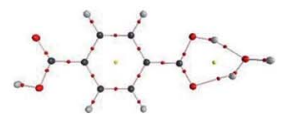

PTA- $\mathrm{H}_{2} \mathrm{O}$

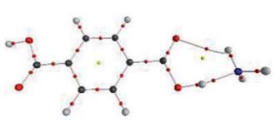

PTA- $\mathrm{NH}_{3}$

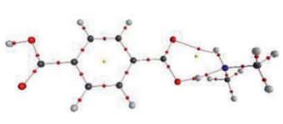

PTA-DMA

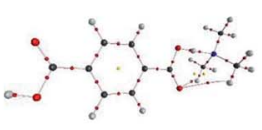

PTA-TMA

Fig. 2 Atom in molecules (AIM) graphs of aromatic acid-containing complexes obtained at the PW91PW91/6-311++G(3df,3pd) level. Red and yellow balls represent bond critical points (BCPs) and ring critical points (RCPs), respectively.

aromatic acid-DMA heterodimer. Thus, we can conclude that aromatic acid $-\mathrm{H}_{2} \mathrm{O}$ complexes are abundant heterodimers due to the high concentration of water in the atmosphere.
Owing to the lower Gibbs free energies of aromatic acid-SA/ $\mathrm{NH}_{3} /$ DMA compared with that of aromatic acid- $\mathrm{H}_{2} \mathrm{O}$, they have a great possibility to form. Although the aromatic acid- 
Table 4 Atoms in molecules (AIM) parameter analysis for aromatic acid-containing complexes calculated at the PW91PW91/6-311++G(3df,3pd) level. Units: a.u

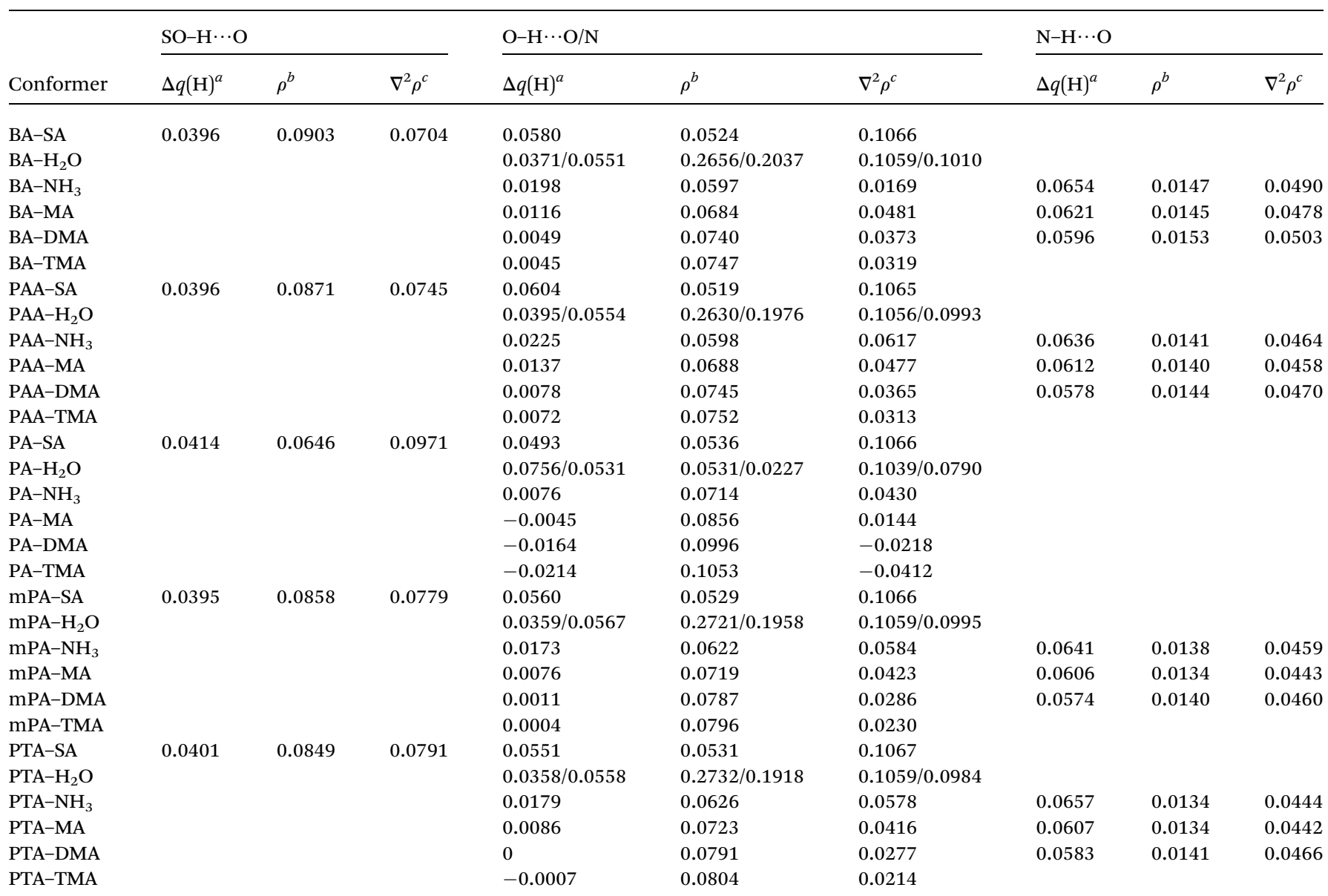

${ }^{a}$ The change in atomic charge at the $\mathrm{H}$ atom. ${ }^{b}$ The electron density at the BCPs. ${ }^{c}$ The Laplacian electron density at the BCPs.

Table 5 Concentrations (molecule per $\mathrm{cm}^{3}$ ) of the complexes from dimerization of aromatic acid and common nucleation precursor calculated by the mass-balance equation

\begin{tabular}{|c|c|c|c|}
\hline Complexes & Concentrations & Complexes & Concentrations \\
\hline BA-SA & $2.98 \times 10^{-4}$ & BA-MA & $8.47 \times 10^{-6}$ \\
\hline $\mathrm{BA}-\mathrm{H}_{2} \mathrm{O}$ & $1.59 \times 10^{-2}$ & BA-DMA & $1.19 \times 10^{-5}$ \\
\hline $\mathrm{BA}-\mathrm{NH}_{3}$ & $3.64 \times 10^{-4}$ & BA-TMA & $2.60 \times 10^{-6}$ \\
\hline PAA-SA & $2.37 \times 10^{2}$ & PAA-MA & $7.41 \times 10^{0}$ \\
\hline $\mathrm{PAA}-\mathrm{H}_{2} \mathrm{O}$ & $1.44 \times 10^{3}$ & PAA-DMA & $5.20 \times 10^{2}$ \\
\hline PAA-NH ${ }_{3}$ & $2.31 \times 10^{2}$ & PAA-TMA & $6.85 \times 10^{-1}$ \\
\hline PA-SA & $9.96 \times 10^{-8}$ & PA-MA & $8.84 \times 10^{-5}$ \\
\hline $\mathrm{PA}-\mathrm{H}_{2} \mathrm{O}$ & $6.71 \times 10^{-4}$ & PA-DMA & $2.06 \times 10^{-4}$ \\
\hline $\mathrm{PA}-\mathrm{NH}_{3}$ & $1.93 \times 10^{-3}$ & PA-TMA & $5.32 \times 10^{-5}$ \\
\hline mPA-SA & $2.08 \times 10^{-6}$ & mPA-MA & $1.70 \times 10^{-7}$ \\
\hline $\mathrm{mPA}-\mathrm{H}_{2} \mathrm{O}$ & $6.50 \times 10^{-5}$ & mPA-DMA & $3.35 \times 10^{-7}$ \\
\hline $\mathrm{mPA}-\mathrm{NH}_{3}$ & $5.23 \times 10^{-6}$ & mPA-TMA & $3.15 \times 10^{-8}$ \\
\hline PTA-SA & $5.50 \times 10^{-5}$ & PTA-MA & $4.51 \times 10^{-6}$ \\
\hline $\mathrm{PTA}-\mathrm{H}_{2} \mathrm{O}$ & $2.16 \times 10^{-3}$ & PTA-DMA & $6.33 \times 10^{-6}$ \\
\hline PTA-NH 3 & $1.94 \times 10^{-4}$ & PTA-TMA & $3.17 \times 10^{-6}$ \\
\hline
\end{tabular}

$\mathrm{SA} / \mathrm{NH}_{3} / \mathrm{DMA}$ has a lower concentration compared with that of aromatic acid- $\mathrm{H}_{2} \mathrm{O}$ complexes, the role of $\mathrm{SA}, \mathrm{NH}_{3}$ and DMA in the dimerization cannot be ignored.

\section{Conclusions}

In summary, we theoretically investigated the molecular interaction between five aromatic acids (BA, PAA, PA, mPA, PTA) and some common atmospheric aerosol nucleation precursors. The following conclusions were drawn from the present study:

(1) The strength of the hydrogen bonds in aromatic acidcontaining complexes could be ranked as follows in descending order: $\mathrm{SO}-\mathrm{H} \cdots \mathrm{O} / \mathrm{N}>\mathrm{CO}-\mathrm{H} \cdots \mathrm{O} / \mathrm{N}>\mathrm{N}-\mathrm{H} \cdots \mathrm{O}$ hydrogen bonds.

(2) The BA/PAA/mPA/PTA-SA complexes had the lowest Gibbs free energy, followed by the BA/PAA/mPA/PTA-DMA complexes. For the PA-containing cluster, PA was more likely to interact with $\mathrm{NH}_{3}$ or amines rather than SA.

(3) For the aromatic monocarboxylic acids, the presence of methyl impeded the complexation process. For the aromatic dicarboxylic acids, the two carboxyl groups in the ortho-position that formed an intra-molecular hydrogen bond promoted the interaction of $\mathrm{NH}_{3}$ and amines, but hindered the interaction of SA. When the two carboxyl groups were in the meta-position and para-position, the extra carboxyl had little influence on the complexation. 
(4) The aromatic monocarboxylic/dicarboxylic acids had similar abilities to interact with SA than did the linear monocarboxylic/dicarboxylic acids, apart from PA. The affinities of the linear monocarboxylic/dicarboxylic acids to $\mathrm{NH}_{3}$ are similar compared with those of the aromatic acid- $\mathrm{NH}_{3}$ complexes.

(5) The atomatic acid- $\mathrm{H}_{2} \mathrm{O}$ clusters have the highest concentrations in the formation of heterodimers. Simultaneously, although the concentrations of aromatic acid-SA/ $\mathrm{NH}_{3}$ / amine clusters are relatively a little low, they also have the potential to form during the formation of heterodimers owing to the relative low Gibbs free energies.

\section{Conflicts of interest}

There are no conflicts to declare.

\section{Acknowledgements}

This work was supported by NSFC (National Natural Science Foundation of China, project no. 91644214, 21677089, 21876102), Shenzhen Science and Technology Research and Development Funds (project no. JCYJ20160510165106371), FRFSDU (the Fundamental Research Funds of Shandong University, project no. 2016WLJH51, 2017JC033), the China Postdoctoral Science Foundation funded project (project no. 2017M612277, 2017T100493), SKLECRA (the open foundation of State Key Laboratory of Environmental Criteria and Risk Assessment, Chinese research academy of environmental sciences no. 2016OFP09).

\section{References}

1 R. Y. Zhang, Science, 2010, 328, 1366-1367.

2 F. Q. Yu and G. Luo, Atmos. Chem. Phys., 2009, 9, 7691-7710. 3 P. Paasonen, A. Asmi, T. Petäjä, M. K. Kajos, M. Äijälä, H. Junninen, T. Holst, J. P. Abbatt, A. Arneth and W. Birmili, Nat. Geosci., 2013, 6, 438-442.

4 F. Q. Yu and A. G. Hallar, J. Geophys. Res.: Atmos., 2014, 119(12), 246-255.

5 R. Y. Zhang, A. Khalizov, L. Wang, M. Hu and W. Xu, Chem. Rev., 2011, 112, 1957-2011.

6 S. Ball, D. Hanson, F. Eisele and P. McMurry, J. Geophys. Res.: Atmos., 1999, 104, 23709-23718.

7 F. Q. Yu and R. P. Turco, J. Geophys. Res.: Atmos., 2001, 106, 4797-4814.

8 S.-H. Lee, J. Reeves, J. Wilson, D. Hunton, A. Viggiano, T. Miller, J. Ballenthin and L. Lait, Science, 2003, 301, 1886-1889.

9 R. Y. Zhang, I. Suh, J. Zhao, D. Zhang, E. C. Fortner, X. X. Tie, L. T. Molina and M. J. Molina, Science, 2004, 304, 1487-1490.

10 J. Zheng, A. Khalizov, L. Wang and R. Y. Zhang, Anal. Chem., 2010, 82, 7302-7308.

11 T. Nieminen, H. E. Manninen, S.-L. Sihto, T. Yli-Juuti, R. L. Mauldin, T. Petaja, I. Riipinen, V.-M. Kerminen and M. Kulmala, Environ. Sci. Technol., 2009, 43, 4715-4721.
12 R. Weber, P. H. McMurry, R. Mauldin, D. Tanner, F. Eisele, A. Clarke and V. Kapustin, Geophys. Res. Lett., 1999, 26, 307-310.

13 A. Chebbi and P. Carlier, Atmos. Environ., 1996, 30, 42334249.

14 J. Duplissy, P. F. DeCarlo, J. Dommen, M. R. Alfarra, A. Metzger, I. Barmpadimos, A. S. Prevot, E. Weingartner, T. Tritscher and M. Gysel, Atmos. Chem. Phys., 2011, 11, 1155-1165.

15 I. G. Kavouras, N. Mihalopoulos and E. G. Stephanou, Nature, 1998, 395, 683.

16 W. F. Rogge, L. M. Hildemann, M. A. Mazurek, G. R. Cass and B. R. Simoneit, Environ. Sci. Technol., 1993, 27, 636-651.

17 I. Suh, R. Y. Zhang, L. T. Molina and M. J. Molina, J. Am. Chem. Soc., 2003, 125, 12655-12665.

18 M. Jang and S. R. McDow, Environ. Sci. Technol., 1997, 31, 1046-1053.

19 K. Kawamura and K. Ikushima, Environ. Sci. Technol., 1993, 27, 2227-2235.

20 T. Kleindienst, M. Jaoui, M. Lewandowski, J. Offenberg and K. Docherty, Atmos. Chem. Phys., 2012, 12, 8711-8726.

21 M. Fraser, G. Cass and B. Simoneit, Environ. Sci. Technol., 2003, 37, 446-453.

22 J. J. Schauer, M. J. Kleeman, G. R. Cass and B. R. Simoneit, Environ. Sci. Technol., 1999, 33, 1578-1587.

23 Y. F. Zhang, Y. Ma, L. Qi, Z. Wang, L. P. Wang and L. Zhu, Environ. Sci., 2016, 37, 2436-2442.

24 C. G. Liu and C. H. Zeng, Chemosphere, 2018, 209, 560-567.

25 K. Kawamura and I. R. Kaplan, Environ. Sci. Technol., 1987, 21, 105-110.

26 W. Xu and R. Y. Zhang, J. Phys. Chem. A, 2012, 116, 45394550.

27 J. R. Lane, J. Contreras-García, J.-P. Piquemal, B. J. Miller and H. G. Kjaergaard, J. Chem. Theory Comput., 2013, 9, 32633266.

28 R. Parthasarathi, V. Subramanian and N. Sathyamurthy, J. Phys. Chem. A, 2006, 110, 3349-3351.

29 J. Zhang and M. Dolg, Phys. Chem. Chem. Phys., 2015, 17, 24173-24181.

30 J. Zhang and M. Dolg, Phys. Chem. Chem. Phys., 2016, 18, 3003-3010.

31 M. J. Frisch, G. W. Trucks, H. B. Schlegel, G. E. Scuseria, M. A. Robb, J. R. Cheeseman, G. Scalmani, V. Barone, B. Mennucci and G. A. Petersson, Gaussian 09, revision A.02, Gaussian, Inc., Wallingford, CT, USA, 2009.

32 J. Elm, M. Bilde and K. V. Mikkelsen, J. Chem. Theory Comput., 2012, 8, 2071-2077.

33 H. R. Leverentz, J. I. Siepmann, D. G. Truhlar, V. Loukonen and H. Vehkamaki, J. Phys. Chem. A, 2013, 117, 3819-3825.

34 H. J. Zhang, O. Kupiainen-Määttä, X. H. Zhang, V. Molinero, Y. H. Zhang and Z. S. Li, J. Chem. Phys., 2017, 146, 184308.

35 R. F. Bader, Chem. Rev., 1991, 91, 893-928.

36 P. Gilli, V. Bertolasi, V. Ferretti and G. Gilli, J. Am. Chem. Soc., 1994, 116, 909-915.

37 L. Curtiss and M. Blander, Chem. Rev., 1988, 88, 827-841.

38 J. Elm, N. Myllys and T. Kurtén, J. Phys. Chem. A, 2017, 121, 4578-4587. 
39 A. B. Nadykto and F. Q. Yu, Chem. Phys. Lett., 2007, 435, 1418.

40 Y. S. Xu, A. B. Nadykto, F. Q. Yu, J. Herb and W. Wang, J. Phys. Chem. A, 2009, 114, 387-396.

41 S.-K. Miao, S. Jiang, J. Chen, Y. Ma, Y.-P. Zhu, Y. Wen, M.-M. Zhang and W. Huang, RSC Adv., 2015, 5, 48638-48646. 42 X.-Q. Peng, Y.-R. Liu, T. Huang, S. Jiang and W. Huang, Phys. Chem. Chem. Phys., 2015, 17, 9552-9563.

43 W. Xu and R. Y. Zhang, J. Chem. Phys., 2013, 139, 064312.

44 A. B. Nadykto, F. Q. Yu, M. Jakovleva, J. Herb and Y. S. Xu, Entropy, 2011, 13, 554-569.

45 Q. Zhang and L. Du, Comput. Theor. Chem., 2016, 1078, 123128.
46 L. Du and H. G. Kjaergaard, J. Phys. Chem. A, 2011, 115, 12097-12104.

47 U. Koch and P. L. Popelier, J. Phys. Chem., 1995, 99, 97479754.

48 S. J. Grabowski, J. Phys. Org. Chem., 2004, 17, 18-31.

49 R. Y. Zhang, A. Khalizov, L. Wang, M. Hu and W. Xu, Chem. Rev., 2011, 112, 1957-2011.

50 F. Riccobono, S. Schobesberger, C. E. Scott, J. Dommen, I. K. Ortega, L. Rondo, J. Almeida, A. Amorim, F. Bianchi and M. Breitenlechner, Science, 2014, 344, 717-721.

51 X. Ge, A. S. Wexler and S. L. Clegg, Atmos. Environ., 2011, 45, 524-546. 